\title{
Pregnancies Following Artificial Insemination with Spermatozoa from Problem Stallion Ejaculates Processed by Single Layer Centrifugation with Androcoll-E
}

\author{
J.M. Morrell, G. Mari, G. Kutvolgyi, S. Meurling, B. Mislei, \\ E. Iacono and Heriberto Rodriguez-Martinez
}

\section{Linköping University Post Print}

N.B.: When citing this work, cite the original article.

This is the pre-reviewed version of the following article:

J.M. Morrell, G. Mari, G. Kutvolgyi, S. Meurling, B. Mislei, E. Iacono and Heriberto Rodriguez-Martinez, Pregnancies Following Artificial Insemination with Spermatozoa from Problem Stallion Ejaculates Processed by Single Layer Centrifugation with Androcoll-E, 2011, Reproduction in domestic animals (1990), (46), 4, 642-645.

which has been published in final form at:

http://dx.doi.org/10.1111/j.1439-0531.2010.01721.x

Copyright: Blackwell Publishing http://www.blackwellpublishing.com/

Postprint available at: Linköping University Electronic Press http://urn.kb.se/resolve?urn=urn:nbn:se:liu:diva-69779 


\section{Pregnancies following artificial insemination with spermatozoa from problem stallion ejaculates processed by Single Layer Centrifugation with Androcoll-E.}

Morrell JM $\mathbf{~}^{1^{*}}$, Mari G ${ }^{2}$, Kútvölgyi $G^{3}$, Meurling $\mathbf{S}^{4}$, Mislei $\mathbf{B}^{2}$, Iacono E ${ }^{2}$, Rodriguez-
Martinez. $\mathbf{H}^{5}$

10

${ }^{1}$ Division of Reproduction, Department of Clinical Sciences, Swedish University of Agricultural Sciences, Box 7054, SE-750 07 Uppsala, Sweden. ${ }^{2}$ Dipartimento Clinico Veterinario Università di Bologna, Italy; ${ }^{3}$ Alebäck Stud Farm, Lidköping, Sweden;

${ }^{4}$ Flyinge AB, 24032 Flyinge, Sweden. ${ }^{5}$ Department of Clinical and Experimental

15 Medicine, Faculty of Health Sciences, Linköping University, SE-581 85 Linköping, Sweden.

* corresponding author, address as above, jane.morrell@kv.slu.se; Tel +4618671152.

20

Running head: fertility of SLC-selected stallion spermatozoa 
35 Key words: stallion spermatozoa, SLC, sperm quality, sperm fertility, AI trial.

\section{Introduction}

A method for improving quality in sperm doses to be used for artificial insemination (AI) is desirable for dealing with some "problem" stallion ejaculates. These can be considered problematic because of their semen characteristics, for example, a low

40 sperm concentration (less than $100 \times 10^{6} / \mathrm{mL}$ ) in a large volume (sometimes over $100 \mathrm{~mL}$ of gel-free ejaculate), or specific problems with sperm morphology or motility.

Alternatively, spermatozoa may not survive cooling, hence restricting their use to on-site AI. Previously some problem ejaculates have been processed by "sperm washing", centrifuging the extended semen to pellet the spermatozoa and removing some of the 
45 seminal plasma, thereby effectively raising the sperm concentration. However, although this procedure results in a transient increase in progressive motility (Parlevliet $\&$ Colenbrander, 1999; Brinsko et al, 2000; Aurich, 2005; Love et al, 2005), it may cause chromatin damage (Morrell et al, 2010a). Density gradient centrifugation (DGC) has been used to select good quality spermatozoa from the rest of the ejaculate and

50 pregnancies have been generated following low-dose AI (deep intrauterine horn; Varner et al, 2008). However, this method of AI is not in widespread use and the sperm yield from DGC is too low (Edmond et al, 2008) for conventional AI. Therefore, new handling strategies are required to enable "problem" ejaculates to be processed for conventional AI.

55 A new method for selecting the best spermatozoa has been developed at the Veterinary Faculty of the Swedish University for Agricultural Sciences (SLU), using Single Layer centrifugation (SLC) through species-specific colloids (Androcoll ${ }^{\mathrm{TM}}$ ). SLCselected sperm samples have good motility, normal morphology, intact plasma membranes and good chromatin integrity (reviewed by Morrell\& Rodriguez-Martinez,

60 2010). The objective of the current case study was to determine if SLC could be used to select sufficient good quality stallion spermatozoa from "problem" ejaculates to be used in conventional AI.

Materials and Methods

Animals and semen collection

65 Warmblood (2) and trotter stallions (3) were housed under standard husbandry conditions at commercial studs, (the Swedish National Stud, Flyinge, Sweden; Alebäck Stud Farm, Lidköping, Sweden) or at the University of Bologna, Italy. The stallions had 
been judged to produce "problem" ejaculates based on semen characteristics and/or low pregnancy rates (0-20\%) following AI with cooled shipped semen doses in the field. All

70 of the stallions were in use as breeding sires for commercial AI. Semen was collected by allowing the stallions to mount a phantom and ejaculate into a warmed artificial vagina (Colorado or Missouri type, depending on the individual). The semen was collected into an insulated glass bottle fitted with a filter to capture gel. Immediately after collection, the ejaculate was extended 1:1 with warm extender, which was either Kenney's extender

75 (Kenney et al, 1975) or INRA96 (IMV, 1'Aigle, France) or skimmed milk medium (modified from Heitland et al, 1996, ie without egg yolk and glycerol) at $37^{\circ} \mathrm{C}$. Semen processing by SLC (all stallions)

The SLC procedure was carried out using Androcoll-E (SLU, Uppsala, Sweden), using one of two protocols, according to the volume of extended ejaculate available. Briefly,

80 where possible, the semen was extended to give an approximate sperm concentration of $100 \times 10^{6} / \mathrm{mL}$, which had previously been determined to be optimal for SLC (Morrell et al, 2010c). The following volumes were used: $4.5 \mathrm{~mL}$ extended semen on top of $4 \mathrm{ml}$ Androcoll-E (SLC-Small) or up to $18 \mathrm{ml}$ extended semen on top of $15 \mathrm{ml}$ Androcoll-E (SLC-Large). After centrifugation at $300 \mathrm{~g}$ for $20 \mathrm{~min}$ in a bench centrifuge with a swing-

85 out rotor, the resulting sperm pellets were removed and resuspended in fresh extender for cooling and transporting as semen doses for AI. Where possible, an aliquot of the sperm suspension was removed for quality control. The insemination was carried out by the veterinarian at the receiving stud according to standard practice.

\section{Case Studies}


90 Stallion 1 was a warmblood stallion, 8-9 years old, which had had a low pregnancy rate in several breeding seasons. Aliquots from four ejaculates were made available for SLCSmall for laboratory assessment only (subjective motility; Morrell et al, 2009a; morphology and chromatin integrity Morrell et al, 2009b), and a further three ejaculates were processed by SLC-Large for AI doses.

95 Stallion 2 was a 10-year old warmblood stallion, producing ejaculates with low or no progressively motile spermatozoa and a high proportion of detached heads. A diagnosis of probable ampullary stasis was made by the stud veterinarian. However, repeated collections over a two month period to "clean out" the partial blockage and remove the accumulated spermatozoa did not resolve the issue of poor sperm quality. In the previous

100 breeding season, aliquots of three ejaculates had shown improved sperm quality after SLC, (Morrell et al, 2010b). Aliquots from five ejaculates were used for SLC with Androcoll ${ }^{\mathrm{TM}}$-E-Large for AI in five mares. Two mares became pregnant, two mares were not pregnant to this $\mathrm{AI}$ and the last mare was barren throughout the season.

Stallion 3, was an 11-year old trotter stallion, which had been producing large volume

105 ejaculates with a low sperm concentration, thus causing a problem in obtaining sufficient spermatozoa for a standard sperm dose (1 billion motile spermatozoa in Sweden) in a manageable volume (ie $\leq 20 \mathrm{~mL}$ ). However, on the day of the SLC, the ejaculate characteristics were normal (volume $50 \mathrm{~mL}$, and sperm concentration $235 \times 10^{6} / \mathrm{mL}$ ). An aliquot of extended semen (15 mL) was prepared by SLC with Androcoll-E-Large.

110 Sperm motility was assessed subjectively by observer 3 (GK), and further aliquots were evaluated for viability, morphology and acrosome staining (Kútvölgyi et al., 2006). The spermatozoa were classified according to morphology (Table 1), viability and acrosome 
status (Figure 1). The SLC-selected sperm sample was used for AI in one mare on the day of SLC, which became pregnant.

115 Stallion 4 was a 13-year old trotter, referred to GM by the stud veterinarian because of low sperm concentration and poor sperm survival in cooled semen doses. No pregnancies had been obtained from semen doses prepared by conventional semen processing in the previous breeding season. Two ejaculates were collected with the following semen characteristics: (i) volume $60 \mathrm{~mL}$, sperm concentration 45 million/mL, motility 70\%; (ii)

120 volume $65 \mathrm{~mL}$, sperm concentration $52 \mathrm{million} / \mathrm{mL}$, motility $65 \%$. On both occasions, the ejaculate was extended 1:1 with skimmed milk semen extender (after Heitland et al, 1996) and then subjected to cushion centrifugation (Cushion Fluid, Minitube, Tiefenbach, Germany) at $00 \mathrm{~g}$ for $13 \mathrm{~min}$ to concentrate the spermatozoa. The resulting sperm sample was split, with one part of the first ejaculate being used for cushion centrifugation to

125 remove some of the seminal plasma followed by DGC (their usual method of preparation), and the other being used for centrifugation using Androcoll -E Small. Sperm motility was evaluated by CASA (Mari et al, 2010). The motility results showed increased total and progressive motility in the centrifuged samples than in the uncentrifuged samples (Table 1), although there was no difference between the two 130 centrifugation treatments (DGC and SLC). For the first ejaculate, the DGC sperm preparation was used for $\mathrm{AI}$ in one mare but did not result in a pregnancy. For the second ejaculate, the SLC-sperm preparation was used for AI in one mare, which became pregnant.

Stallion 5 was a 24-year old trotter, referred to GM by the stud veterinarian because of 135 large semen volume, relatively poor quality (approximate values: volume $100 \mathrm{~mL}$, sperm 
concentration $<200$ million/mL, motility $50 \%$ ), and poor sperm survival in cooled semen. The pregnancy rate after AI with conventionally prepared semen doses in the previous breeding season had been approximately $20 \%$. Eight ejaculates were collected and were immediately extended in skimmed milk extender (as for Stallion 4). One aliquot 140 was used for cushion centrifugation at $400 \mathrm{~g}$ for $13 \mathrm{~min}$ with $3 \mathrm{ml}$ cushion fluid (T1), and the other (15 mL) was subjected to SLC with Androcoll-E Large at $300 \mathrm{~g}$ for $20 \mathrm{~min}$ (T2) (Morrell et al, 2009c). Sperm pellets were resuspended in fresh skimmed milk medium, and all sperm samples including the untreated aliquots $(\mathrm{N})$ were used for CASA (Mari et al, 2010), immediately (0h) and after 24h. In some cases, namely the last three ejaculates

145 for Stallion 5, sperm motility was also analysed after 48h. The remainder of the sperm samples from T1 and T2 were used for AI after 24h. Mean values for motility were compared using student's t test, with significant differences defined as $\mathrm{P}<0.05$. The CASA motility results are shown in Table 1 . Total motility and progressive motility were significantly better for $\mathrm{T} 1$ and $\mathrm{T} 2$ than for $\mathrm{N}(\mathrm{P}<0.05)$. There was no difference between

$150 \mathrm{~T} 1$ and $\mathrm{T} 2$ at $0 \mathrm{~h}$ or $24 \mathrm{~h}$, although $\mathrm{T} 2$ (the SLC-samples) had better mean values than T1 (sperm washing) after $48 \mathrm{~h}$ cold-storage $(\mathrm{P}<0.05)$. For AI with $\mathrm{T} 1,5$ out of 11 mares became pregnant and for $\mathrm{T} 2$, three out of eight mares became pregnant.

\section{Discussion}

Previously, sperm quality had been improved (according to laboratory analyses)

155 by SLC of stallion spermatozoa using Androcoll-E (Morrell \& Rodriguez-Martinez, 2010). The results presented here indicated not only that sperm quality could be improved by SLC for four out of the five stallions, but also that sufficient spermatozoa could be 
recovered after SLC-processing by stud personnel for conventional AI resulting in pregnancies.

For stallions 4 and 5, a comparison was made between SLC and "sperm washing" i.e. centrifugation without a colloid. Previous studies have shown that SLC is better than "sperm washing" in that selection is made for motile spermatozoa with good chromatin integrity, whereas sperm washing samples show only a transient improvement in sperm motility and no improvement in chromatin integrity (Morrell et al, 2010a). In the present

165 study, washed samples and SLC-selected samples had better motility than the corresponding uncentrifuged samples, although there was no difference in sperm motility between the two methods at $\mathrm{t} 0$ or $\mathrm{t} 24$. By $\mathrm{t} 48$, however, sperm motility in the washed samples was deteriorating whereas the SLC-samples retained their motility. There was no difference in pregnancy rates between the two treatment groups (AI at $24 \mathrm{~h}$ after SLC), 170 although the sample size was small.

Unfortunately it was not possible to perform "control” AI, i.e. using non-SLC selected spermatozoa, for any of the ejaculates described here because the low quality of the untreated ejaculates precluded them from being used for commercial AI doses. A stud does not wish to harm its reputation by supplying poor-quality semen doses for AI.

175 However, there was sufficient documented evidence of the poor fertility of some of these stallions (stallions 1 and 5 each had $20 \%$ pregnancy rate previously from AI with unselected spermatozoa; semen from stallions 2 and 4 was deemed to be of too poor quality to be used for AI doses) to be confident that the improvements in sperm quality seen in the laboratory analyses were likely to be associated with the pregnancies

180 following AI with SLC-selected spermatozoa. Of course, it should be born in mind that 
the number of mares used for AI was very low, but even so the results obtained are encouraging and would appear to offer a solution for equine breeders faced with these problem stallions. Our aim in publishing these results is to make public the existence of this procedure so that equine breeders can choose if they want to use it for problem

185 stallions or not. In this way it should be possible to recruit more mares and more stallions to the project, thus eventually achieving a larger sample size than has been possible to date. The problem stallions used thus far represent some examples of the many different types found in the field; the study is continuing, including more stallions with different types of problems.

It was interesting to note that the SLC-samples from stallion 2, which was thought to have temporary ampullary stasis, did not show an improvement in normal morphology or chromatin integrity, compared to the non-SLC samples. It appeared that the detached heads pelleted along with the normal spermatozoa during centrifugation, a phenomenon that has been reported previously (Morrell et al, 2010b). Moreover, the SCSA result

195 indicated more chromatin damage in the SLC-sample than in the non-SLC sample from the same ejaculate. These results are contrary to the results reported for more than 100 ejaculates, where both normal morphology $(+11 \%$; $\mathrm{P}<0.001)$ and chromatin damage $(-$ $5.1 \% \mathrm{DFI} ; \mathrm{P}<0.001)$ were improved in the SLC samples compared to the corresponding uncentrifuged samples (Morrell et al, 2010c), and are also in contrast to results from 200 sperm samples from the same stallion taken the previously when he was not affected by ampullary stasis. It is interesting to speculate whether the raised \%DFI in the SLC samples from this stallion was due to the presence of the detached heads, which had been concentrated by the centrifugation process. Alternatively, ampullary stasis per se could 
have a detrimental effect on chromatin integrity in the centrifuged samples, perhaps due

205 to changes in the seminal plasma affecting the sperm membranes and making them more susceptible to damage during centrifugation, thus causing a small rise in \%DFI.

Further studies are underway to identify which types of problem ejaculates can be improved by Single Layer Centrifugation as a practical solution to improving stallion sperm quality. In the meantime, it can be concluded from the results presented here that

210 SLC can be used by stud personnel to process "problem" ejaculates, that sperm quality is generally improved in the SLC-selected samples and that the SLC-selected spermatozoa are capable of fertilization after AI.

\section{Source of Funding:}

We thank the Swedish Foundation for Equine Research (project H0747189), and the

215 Lagerlöf Foundation, KSLA, Stockholm for funding this study.

\section{Conflict of Interest:}

None

\section{Acknowledgement:}

We are grateful to Annika Rikberg and Karin Selin-Wretling for the morphology analysis 220 and Dr Anders Johannisson for the SCSA.

\section{References}

Aurich C, 2005: Factors affecting the plasma membrane function of cooled-stored stallion spermatozoa. Animal Reproduction Science 89 65-75.

225 Brinsko SP, Crockett EC, Squires EL, 2000: Effect of centrifugation and partial removal of seminal plasma on equine spermatozoal motility after cooling and storage. Theriogenology 54 129-136. 
Edmond AJ, Teague AR, Brinsko SP, Comerford KL, Waite JA, Mancill SS, Love CC, Varner DD, 2008: Effect of density gradient centrifugation on quality and recovery of equine spermatozoa. Anim. Reprod. Sci. 107 Abst.16, 318.

Heitland AV, Jasko DJ, Squires EL, Graham JK, Pickett BW, Hamilton C, 1996: Factors affecting motion characteristics of frozen-thawed stallion spermatozoa. Equine Vet J. $2847-53$.

Kenney RM, Bergman RV, Cooper WL, Morse GW, 1975: Minimal contamination techniques for breeding mares: techniques and preliminary findings. Proc. Am. Assoc. Equine Practice 21 327-336.

Kútvölgyi G, Stefler J, Kovács A, 2006: Viability and acrosome staining of stallion spermatozoa by Chicago sky blue and Giemsa. Biotechnic \& Histochemistry 81 $109-117$.

240 Love CC, Brinsko SP, Rigby SL, Thompson JA, Blanchard TL, Varner DD, 2005 Relationship of seminal plasma level and extender type to sperm motility and DNA integrity. Theriogenology 63 1584-1591.

Mari G, Rizzato G, Merlo B, Iacono E, Bucci D, Seren E, Tamanini C, Galeati G, Spinaci M, 2010 Quality and Fertilizing Ability In Vivo of Sex-Sorted Stallion Spermatozoa. Reprod Dom Anim 45 331-335.

Morrell JM, Johannisson A, Dalin A-M, Rodriguez-Martinez H, 2009: Single Layer Centrifugation with Androcoll-ET can be scaled-up to allow large volumes of stallion ejaculate to be processed easily. Theriogenology 72 879-884.

Morrell JM, Dalin A-M, Rodriguez-Martinez H, 2009a: Comparison of density gradient 250 and single layer centrifugation of stallion spermatozoa: yield motility and survival. Equine Veterinary Journal 41 53-58. 
Morrell JM, Johannisson A, Dalin A-M, Rodriguez-Martinez H, 2009b: Morphology and chromatin integrity of stallion spermatozoa prepared by density gradient and single layer centrifugation through silica colloids. Reprod. Domest. Anim. 44 512-517.

255 Morrell JM, Rodriguez-Martinez H 2010: Practical applications of sperm selection techniques as a tool for improving reproductive efficiency. Veterinary Medicine International doi:10.4061/2011/2984767

Morrell JM, Rodriguez-Martinez H, Johannisson A, 2010a: Single layer centrifugation of stallion spermatozoa improves sperm quality compared with sperm washing.

260 Reproductive Biomedicine Online doi:10.1016/j.rbmo.2010.03.027.

Morrell JM, Rodriguez-Martinez H. \& Johannisson A. 2010b: Single Layer

Centrifugation of stallion spermatozoa consistently selects the most robust spermatozoa from the rest of the ejaculate in a large sample size: data from 3 breeding seasons. Equine Veterinary Journal 42 579-585.

265 Parlevliet JM, Colenbrander B, 1999: Prediction of first season stallion fertility of 3-yearold Dutch Warmbloods with prebreeding assessment of percentage of morphologically normal live sperm. Equine Veterinary Journal 31 248-251.

Varner DD, Love CC, Brinsko SP, Blanchard TL, Hartman DL, Bliss SB, Carroll BS, Eslick MC, 2008: Semen Processing for the Subfertile Stallion. Journal of Equine

270 Veterinary Science 28 677-685 
Table 1: Summary of results for "problem" ejaculates from five stallions processed by SLC.

\begin{tabular}{|c|c|c|}
\hline Case Study & Sperm quality before and after SLC & AI results \\
\hline Stallion 1 & $\begin{array}{l}\text { motility } 60 \pm 10 \% \text { versus } 77.5 \pm 2.9 \% \text {, normal } \\
\text { morphology } 34 \pm 6.3 \text { versus } 59.5 \pm 24.3, \% \text { DFI } \\
18 \pm 4.5 \% \text {.versus } 7 \pm 1.1 \%\end{array}$ & $\begin{array}{l}\text { Control 1/5, } \\
\text { SLC 2/3 }\end{array}$ \\
\hline Stallion 2 & $\begin{array}{l}\text { Previous year: } \\
\text { motility } 65 \% \text { versus } 90 \% \text {, normal morphology } 68 \% \\
\text { versus } 89.5 \%, \% \text { DFI } 18.6 \% \text { versus } 3.4 \% \\
\text { Problem year: } \\
\text { viability } 67 \% \text { versus } 69 \% \text {; } \% \text { DFI } 19 \% \text { versus } 24 \% \\
\text { for SLC-selected and control samples, respectively). } \\
\text { Normal morphology in control } 67 \% \text { but } 11 \% \\
\text { detached heads }\end{array}$ & $\begin{array}{l}\text { Control not } \\
\text { done (quality } \\
\text { too poor); } \\
\text { SLC } 2 / 4 \text { (plus } \\
\text { one barren } \\
\text { mare } \\
\text { inseminated) }\end{array}$ \\
\hline Stallion 3 & $\begin{array}{l}\text { Motility } 70 \% \text { versus } 90 \% \text { at } 0 \mathrm{~h}, 40 \% \text { versus } 80 \% \\
\text { after } 24 \mathrm{~h} \text {. } \\
\text { Viability } 66 \% \text { versus } 81 \% \text { at } 0 \mathrm{~h}, 51 \% \text { versus } 71 \% \\
\text { after } 24 \mathrm{~h} \text {; } \\
\text { Morphology } 71 \% \text { versus } 86 \% \text { at } 0 \mathrm{~h}, 74 \% \text { versus } \\
84 \% \text { after } 24 \mathrm{~h} \text {. }\end{array}$ & SLC 1/1 \\
\hline Stallion 4 & $\begin{array}{l}\text { CASA motility: Expt.1 Control TM 65\% PM 17\%; } \\
\text { DGC TM 86\% PM 36\%; SLCTM 88\% PM 30\% } \\
\text { CASA motility: Expt } 2 \text { Control TM 71\% PM 23\%; } \\
\text { DGC TM 85\% PM 25\%; SLCTM } 77 \% \text { PM 36\% }\end{array}$ & $\begin{array}{l}\text { DGC 0/1 } \\
\text { (expt. 1); } \\
\text { SLC } 1 / 1(\text { expt. } \\
\text { 2) }\end{array}$ \\
\hline Stallion 5 & $\begin{array}{l}\text { CASA 24h: control TM 20\% PM 6\%; cushion cent } \\
\text { TM 30\% PM 12\%; SLC 29\% PM 14\%. } \\
\text { CASA 48h: control TM 10\% PM 1\%; cushion cent } \\
\text { TM 19\% PM 5\%; SLC TM 20\% PM 11\%. }\end{array}$ & $\begin{array}{l}\text { Cushion cent } \\
\text { 5/11: } \\
\text { SLC } 3 / 8\end{array}$ \\
\hline
\end{tabular}


Figure 1: Stallion spermatozoa stained with Chicago Sky Blue and Giemsa, showing examples of live and dead spermatozoa (a), acrosome status and various

280 morphological abnormalities (a and b).
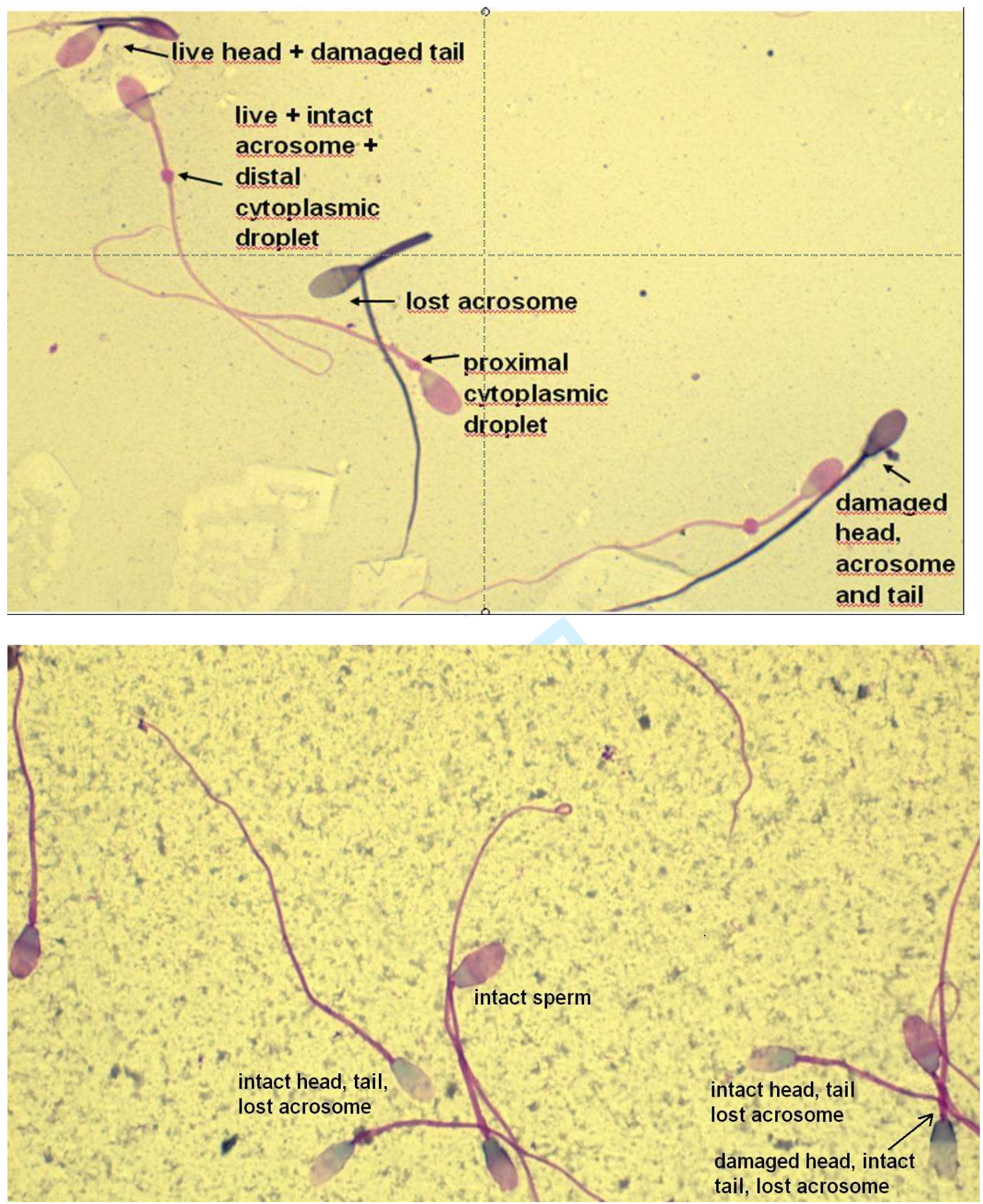